\title{
Summer ice dynamics during SHEBA and its effect on the ocean heat content
}

\author{
Jagkie A. Righter-Menge, ${ }^{1}$ Donald K. Perovich, ${ }^{1}$ W. Scott Pegau ${ }^{2}$ \\ ${ }^{1}$ U.S. Army Cold Regions Research and Engineering Laboratory, 72 Lyme Road, Hanover, NH 03755-1290, U.S.A. \\ ${ }^{2}$ College of Oceanic and Atmospheric Sciences, Oregon State University, Corvallis, OR 97331, U.S.A.
}

\begin{abstract}
Winter ice dynamics plays an important role in the energy budget of the air-ice-ocean system, through the formation of leads and ridges. In summer, thermodynamic processes cause a transition in the ice pack from a mechanical continuum to an ensemble of floes that move in a state of free drift, with little floe-floe interaction. Results from the recent Surface Heat Budget of the Arctic Ocean (SHEBA) experiment have demonstrated that even under summer conditions, ice dynamics can still cause dramatic changes in the characteristics of the ice- ocean matrix that affect the energy budget. To illustrate this, we present observations taken before and after a period of sustained, moderate winds in late July 1998, which was preceded by an extended period of low winds. These conditions resulted in significant differential motion of ice floes in the vicinity of SHEBA. The measurements include the mass balance of the ice cover, the distribution of ice and open water, and salinity and temperature profiles in leads. The data show that after the storm there was a significant change in the amount and distribution of open-water areas, that there was an increase in the rate of bottom ablation, and that a stratified layer of warm fresh water that had formed at the top of leads during melt had become mixed.
\end{abstract}

\section{INTRODUCTION}

In the polar regions, the energy exchange between the atmosphere and the ocean is greatly moderated by the presence of a sea-ice cover. The thickness distribution of the ice cover is key to the complex interaction between the atmosphere, ice and ocean. During the growth season, sea-ice dynamics can cause abrupt and significant changes in the ice-thickness distribution. For much of the growth season the ice cover is nearly continuous, allowing internal stresses to develop in the ice as it resists movement due primarily to wind and ocean current forcing (Steele and others, 1997; Overland and others, 1998). When the internal stresses become high enough, leads (cracks in the ice) and ridges form (Coon and others, 1998; RichterMenge and Elder, 1998). The open and newly freezing leads provide a large thermal contrast between the cold atmosphere and the relatively warm ocean. Studies have indicated that even though leads and young ice typically constitute only a small fraction of the ice cover during the growth season, they significantly impact the thermodynamics of the ice cover (Badgley, 1966; Maykut, 1978, 1982; Gow and others, 1990; Perovich and Richter-Menge, 2000; Wettlaufer and others, 2000). Additionally, the heat released into the atmosphere when a lead forms can result in forced convection in the atmospheric boundary layer (Schnell and others, 1989; Andreas and others, 1990; Pinto and Curry, 1995; Pinto and others, 1995), and the dense brine rejected by the growing ice causes mixing in the upper ocean (Smith, 1973; Smith and others, 1990; Morison and others, 1992).

The focus of this paper is on summer conditions, when the ice cover is tranformed into a matrix of ice and open water. Under these conditions, there are no internal ice stresses and the ice floes are said to be in a state of free drift.
This period is characterized by a strong correlation between the movement of the ice floes and the wind velocity (McPhee, 1980; Steele and others, 1997). Further, during the summer, air temperatures are near $0^{\circ} \mathrm{C}$ and the solar radiation input is at its maximum. This results in a minimal thermal contrast between the atmosphere and the ocean, and significant melting of the snow and ice cover.

Results from Perovich and Maykut (1990) and Golovin and others (1994) have shown that under quiescent conditions a warm, fresh-water layer develops at the top of leads from the melt runoff. McPhee and others (1987) consider the distribution of heat and salt in the upper ocean under considerably more turbulent conditions, when the water at the top of the leads is well mixed. During the recent Surface Heat Budget of the Arctic Ocean (SHEBA) experiment, we had the opportunity to observe a transition between these two states. Measurements of ice mass balance, water temperature and salinity in the top of leads, and the distribution of open-water areas, were made before, during and after the transition. By combining and comparing these data, we can assess the impact of ice dynamics on the surface heat budget during the summer.

\section{FIELD MEASUREMENTS}

The measurements and observations considered in this paper were made during the SHEBA field experiment, which was conducted from October 1997 to October 1998 (Perovich and others, 1999a, b; http://arcss.colorado.edu/). We used measurements of the salinity and temperature of the water in the upper few meters of leads, the ice mass balance, the motion of the ice pack in the vicinity of Ice Station SHEBA, the ice surface characteristics, the wind 
speed at a height of $2 \mathrm{~m}$ above the ice surface and the speed of the ice floe that served as a base for Ice Station SHEBA.

Time series of salinity and temperature measurements were made in the top few meters of two leads adjacent to the SHEBA main floe. At one site (Seattle), these measurements were made using a YSI Model 30 temperature and conductivity meter, with a salinity and temperature accuracy of $0.1 \mathrm{psu}$ (practical salinity units) and $0.1{ }^{\circ} \mathrm{C}$, respectively. The probe was tied to a series of connected PVC rods and lowered into the water from the edge of the ice floe. Measurements were made every $10 \mathrm{~cm}$ in the top $2 \mathrm{~m}$ of the water. Profiles were typically made every other day, starting on 4 July and ending 9 August. At the second site (Sarah's Lake), more detailed upper ocean measurements were made using a profiling conductivity-, temperature- and depth-measuring device (CTD), with accuracies of $0.01 \mathrm{psu}$ and $0.005^{\circ} \mathrm{C}$. Measurements were made from a small motorized boat, equipped with a global positioning system (GPS). These profiles were made on a daily basis, starting on 10 June and ending 9 August. They typically extended $10 \mathrm{~m}$ below the water surface, with occasional casts to $60 \mathrm{~m}$.

Helicopter surveys of leads in the area surrounding Ice Station SHEBA $(<30 \mathrm{~km}$ from the ship that served as a base for Ice Station SHEBA) were conducted on four occasions during the summer. Salinity and temperature profiles were collected at several points within each lead from a hovering helicopter. The profiling CTD was used to collect these measurements in the top 5-10 $\mathrm{m}$ of the water. A GPS was used to determine the position of the leads relative to the ship.

Mass-balance measurements were made at $>100$ sites on the SHEBA main floe, including the two lead sites. The massbalance sites consisted of an ablation stake and thickness gauge, which allowed us to determine the growth and ablation rate at the top and bottom surface of the sea-ice cover.

An array of 12 remote-measurement sites was deployed around Ice Station SHEBA at the beginning of the field program. Each of the sites included a buoy that monitored the position of the site, using either the ARGOS system or GPS (Overland and others, 1998; Richter-Menge and others, 1998). The sites were originally located $15-80 \mathrm{~km}$ from Ice Station SHEBA. The position of Ice Station SHEBA was monitored using the ship's GPS system. On average, we obtained hourly readings of the positions of all these sites.

A helicopter was also used to make surveys of surface characteristics, including the relative amounts of bare ice, ponded ice and open water. Between 17 May and 3 October, a total of 12 surveys were conducted. Each survey was done using a $50 \mathrm{~km}$ modified box pattern, centered on Ice Station SHEBA. Color $35 \mathrm{~mm}$ photographs were taken at set intervals throughout the flight. On a typical mission, > 200 photographs were taken, each covering an area of approximately $1 \mathrm{~km}^{2}$. These were subsequently interpreted using an image analysis technique that could distinguish between the various surface types by their color (Perovich and others, in press b).

\section{THE MAIN EVENT}

A significant meteorological event in late July dramatically altered the characteristics of the ice cover in the neighborhood of Ice Station SHEBA. During most of July, winds were light, averaging about $2.1 \mathrm{~m} \mathrm{~s}^{-1}$ (Fig. 1). On 26 July they began to increase. They reached an initial peak of $6.1 \mathrm{~m} \mathrm{~s}^{-1}$, decreased to $2.1 \mathrm{~m} \mathrm{~s}^{-1}$ and began to increase again on 27 July. Over the

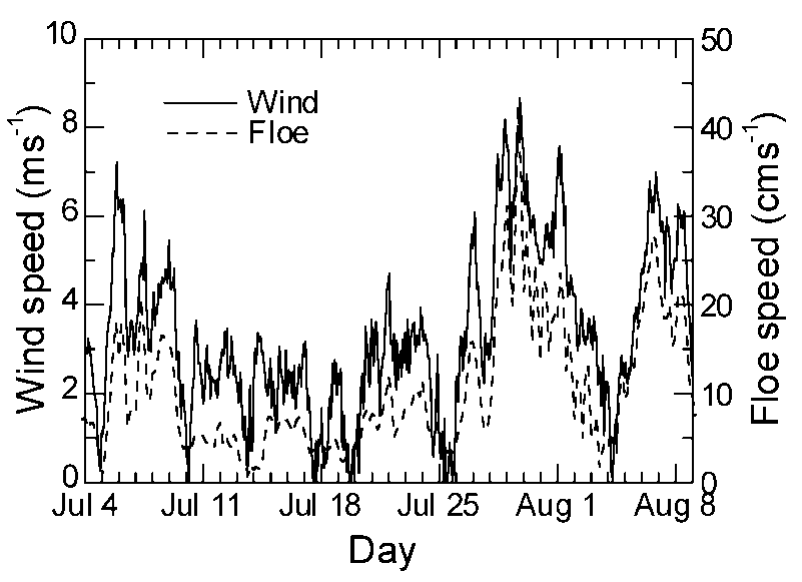

\section{Fig. 1. Time series of wind and ice floe speed during the height} of the summer melt season, 1 July-15 August 1998.

next 4 days, until 1 August, they remained moderate, reaching a maximum of approximately $8 \mathrm{~m} \mathrm{~s}^{-1}$. The average wind speed between 27 July and 1 August was $6.1 \mathrm{~m} \mathrm{~s}^{-1}$. Winds died down after 1 August, reaching a low of near $0 \mathrm{~m} \mathrm{~s}^{-1}$ on 4 August.

The drift speed of the ice floe that served as a base for Ice Station SHEBA increased in response to the increased wind speed, reaching peak speeds of about $0.40 \mathrm{~m} \mathrm{~s}^{-1}$. Figure 1 shows, in general, that the speed of the ice corresponded closely to the wind speed. The average ratio of the ice-floe speed to the wind speed between 1 July and 15 August was $0.030 \pm 0.009$. This suggests that the ice pack had reached a state of free drift by 1 July. This observation is consistent with model studies and field measurements, which indicate that when the ice in the central Arctic is in a state of free drift its movement is dominated by the air and water drag. Internal stresses in the ice cover, which develop as the ice resists movement, are negligible. (McPhee, 1980; Steele and others, 1997).

\section{RESULTS}

The effects of this event were evident on looking out from the ship's bridge after the winds had abated: on 3 August there was noticeably more open water around Ice Station SHEBA. In particular, the area of Sarah's Lake increased from $14000 \mathrm{~m}^{2}$ to $>300000 \mathrm{~m}^{2}$. The position of the Seattle site, relative to the ship's heading, also changed significantly. Until the winds increased, the Seattle site had been slightly to the right of the bow, at a distance of $0.5 \mathrm{~km}$. At the end of the event, it had drifted to the ship's port side and was $1.5 \mathrm{~km}$ from the ship. Another anecdotal indication of the storm's impact on the distribution of ice and open water was a change in the mode of travel to and from the Seattle site. Before the storm we could get to the site from the ship on foot, using a small rowboat to cross an area of open water that was approximately $100 \mathrm{~m}$ across. After the storm the only way to reach the Seattle site was by helicopter, because of the increase in distance from the ship and the increase in open water along the way. It is interesting to note that the divergence in the ice cover occurred after the winds had diminished, rather than during the peak of the storm. This suggests that the divergence was caused by a variation in the deceleration rate of the individual floes.

These observations are quantitatively substantiated by measurements of the relative motion of the position buoys 


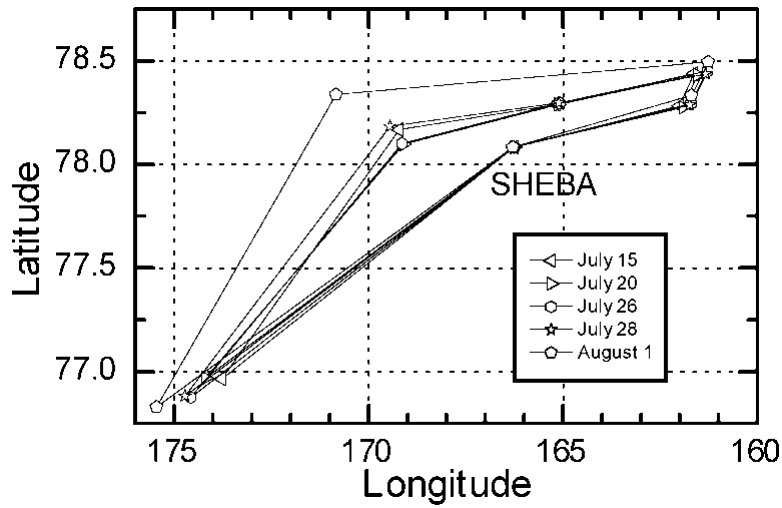

Fig. 2. Time series of relative motion of the position buoys located around Ice Station SHEBA, 15 July-1 August 1998.

surrounding Ice Station SHEBA. In Figure 2, we present a time series of the positions of the buoys relative to the location of Ice Station SHEBA on 15 July 1998. At this point in the experiment, 5 of the original 12 buoys were still operational, varying in distance from Ice Station SHEBA from $18 \mathrm{~km}$ to $118 \mathrm{~km}$. We chose to use the relative motion of the buoys for ease of comparison. To do this, the drift of Ice Station SHEBA was subtracted from the drift of each position buoy on each of the days considered. The result is that Ice Station SHEBA appears stationary in Figure 2, when in fact over this 18 day period the ice station drifted a total of about $35 \mathrm{~km}$, generally to the northeast.

There is clearly a change in the relative positions of the buoys around Ice Station SHEBA, which coincides with the increased winds. This is indicated by a change in the area defined by the boundaries of the array. Between 15 July and 28 July, the area bounded by the array increased by $15 \%$, from $7000 \mathrm{~km}^{2}$ to $8000 \mathrm{~km}^{2}$. The shape of the array remained consistent during this period. Between 28 July and 1 August, the area bounded by the array increased rapidly and significantly, to $13000 \mathrm{~km}^{2}$, an increase of $64 \%$ in 5 days. The increase in area was primarily due to the relatively large displacement of the buoy to the northwest and west of SHEBA. The buoy closest to SHEBA, in a northeast direction, was lost during this period, but it is presumed that the floe that contained this buoy also underwent a relatively large displacement. The buoy to the northwest of SHEBA was lost after 1 August, preventing us from determining the area of the array on 3 August, when we observed the most significant changes in the distribution of ice and open water in the immediate vicinity of Ice Station SHEBA.

A comparison of the results from the helicopter surveys to determine the relative amounts of ice, ponds and open water on 25 July and 7 August is consistent with the results from the buoy array (Perovich and others, in press b). On 25 July, the distribution of surface types was $73 \%$ bare ice, $22 \%$ ponded ice and 5\% open water. By 7 August, there had been a significant increase in the amount of open water, to $19 \%$. The bare-ice and ponded-ice fractions were reduced to $63 \%$ and $18 \%$, respectively.

The salinity and temperature profiles in the top of the lead at the Seattle site showed that there was also a dramatic change in the surface characteristic of the open-water areas before and after the storm (Fig. 3). The Seattle site was located on undeformed multi-year ice. Between 4 and 26 July, a wellmixed, warm, relatively fresh-water layer developed in the top of the lead, adjacent to the multi-year floe. This was a period

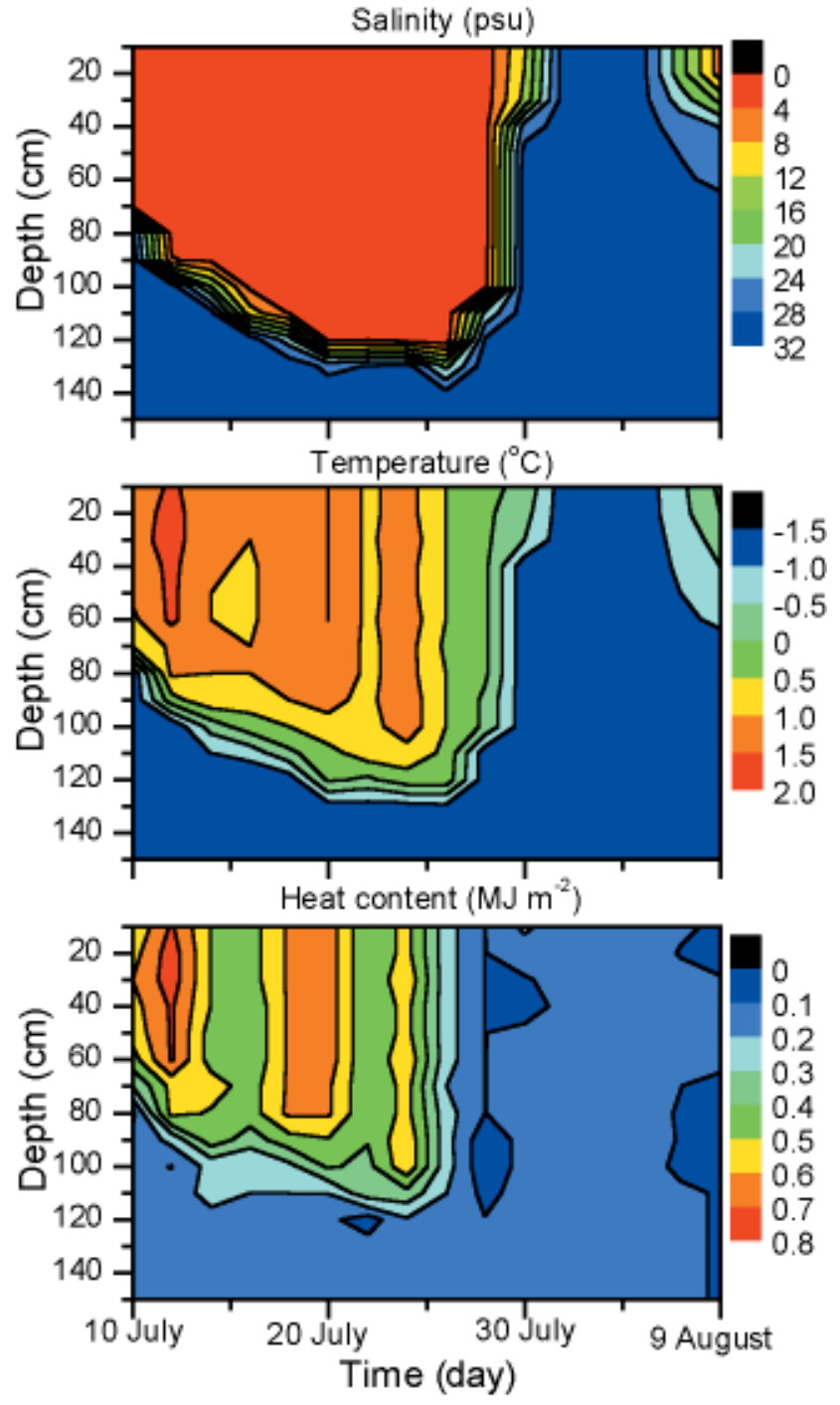

Fig. 3. Contours of (a) salinity, (b) temperature and (c) heat content in the water at the top of a lead adjacent to an undeformed multi-year floe, 10 fuly-8 August 1998.

when winds were light and there was little differential movement of the ice floes in the vicinity of Ice Station SHEBA. Others have observed the formation of a fresh-water layer in the central Arctic under quiescent conditions, including Nansen during the drift of the Fram (Nansen, 1902). The source of water for this layer is the melting snow and ice that run off the surface into the lead (Perovich and Maykut, 1990; Golovin and others, 1994). As the relatively fresh meltwater collects in the lead, it remains on the top of the lead because it is more buoyant than the colder and saltier ocean water that underlies it. Evidence of significant surface melting at the Seattle site is provided by the measurements from five mass-balance sites, originally located 5-27 $\mathrm{m}$ from the edge of the ice floe immediately adjacent to the site where we measured lead characteristics. Between 4 and 26 July, the average amount of surface melting near the lead at the Seattle site was $26 \mathrm{~cm}$.

At the Seattle site the depth of the fresh-water layer increased from $70 \mathrm{~cm}$ on 10 July to $120 \mathrm{~cm}$ on 26 July. The thickness of the transition layer between the relatively warm, fresh-water layer and the underlying ocean remained relatively constant for this entire period, at $20-30 \mathrm{~cm}$. Between 16 July and 26 July, the salinity in the surface layer reached a minimum, at $0.7-0.9 \mathrm{psu}$. The temperature of the layer ranged from $+0.9^{\circ}$ to $+1.5^{\circ} \mathrm{C}$ during this same period. 
While the salinity of the water layer either decreased with time or was stable, the temperature varied. For example, the maximum temperature of the surface layer was reached relatively early in its formation: $+1.7^{\circ} \mathrm{C}$ on 12 July. Whilst we have not definitely determined the reason for the temperature fluctuations, we expect they are related, in part, to changes in the heat flux caused by variations in the amount of cloud cover. Other contributing factors could be the growth and melting of thin ice layers that were observed to form on the top of the lead and changes in the horizontal transport of heat.

On 6 July, the average thickness of the undeformed multi-year ice adjacent to the lead, based on the five massbalance sites near the edge of the floe, was $204 \mathrm{~cm}$. By 28 July, the average thickness of the ice cover had decreased to $152 \mathrm{~cm}$, due to melting at both the top and bottom ice surfaces. Based on these observations, it seems likely that the warm fresh-water layer in the lead was near, if not slightly below, the multi-year ice by 26 July.

The salinity and temperature profiles on 28 July, soon after the winds began to increase, show a decrease in the depth of the fresh-water layer to $100 \mathrm{~cm}$. There was a slight increase in the water's salinity and a slight decrease in the temperature. By 30 July the layer was only $40 \mathrm{~cm}$ deep and by 1 August it had disappeared. The disappearance of the layer coincides with the increase in the rate of movement of the ice floes and the increase in their differential motion (Figs 1 and 2). It appears that the increased winds created enough interfacial stress to generate the turbulence necessary to mix the fresh-water layer with the underlying ocean water.

The development and destruction of this warm freshwater layer were prevalent in the leads in the area around Ice Station SHEBA. Time-series measurements of the salinity and temperature of the surface water at the top of Sarah's Lake are consistent with the observations at the Seattle site. The measurement record at Sarah's Lake was longer and more detailed than at the Seattle site, beginning in early June. Thus, it provides a more complete record of the development of the warm fresh-water layer. On 26 June, a $5 \mathrm{~cm}$ thick layer of water with a salinity of 2.5 psu and temperature of $0.6^{\circ} \mathrm{C}$ was observed at the top of Sarah's Lake. A sharp, $35 \mathrm{~cm}$ thick transition layer existed under the relatively fresh-water lens. On 26 July the warm fresh-water layer had reached a thickness of $120 \mathrm{~cm}$ and was underlaid by a $20 \mathrm{~cm}$ thick transition layer. The salinity and temperature of the relatively fresh layer was $1.3 \mathrm{psu}$ and $+1.0^{\circ} \mathrm{C}$, respectively. Sarah's Lake was adjacent to first-year ice, which was $108 \mathrm{~cm}$ thick on $26 \mathrm{July}$. Here, the warm fresh-water layer eventually extended laterally beneath the ice cover. As was observed at the Seattle site, the layer was gone on 1 August. The time series at Sarah's Lake indicates that the warm fresh-water layer persisted for 36 days, or nearly 5 weeks.

The results from helicopter CTD surveys, taken on 22 July to measure water salinity and temperature profiles at the surface of eight leads within $30 \mathrm{~km}$ of Ice Station SHEBA, are presented in Figure 4. The prevalence of the warm freshwater layer observed at the Seattle site and at Sarah's Lake is readily apparent. There were variations in the characteristics of the well-mixed surface layer between these leads, including the depth of the layer, the thickness of the transition layer and the salinity and temperature of the layer. Temperature variations in the top layer were larger than variations in the salinity. These variations are believed to be the result of lead size and time since opening (temperature) and surrounding ice thickness (depth of fresh-water layer).

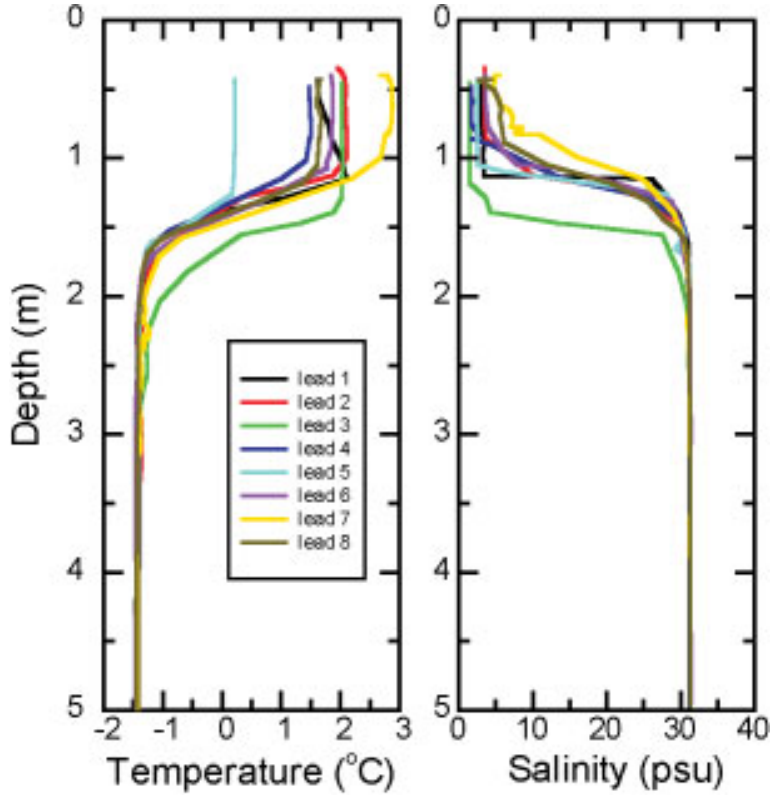

Fig. 4. Temperature and salinity profiles of the water in the top of leads within $30 \mathrm{~km}$ of Ice Station SHEBA, 22 July 1998.

\section{DISGUSSION}

Changes in the thickness, salinity and temperature of the water at the top of the leads affected the heat content of this layer. The amount of heat available for melting in a unit area of water, $Q\left(\mathrm{~J} \mathrm{~m}^{-2}\right)$, is a function of the difference between the temperature of the water and its freezing point:

$$
Q=\rho_{\mathrm{w}} c_{\mathrm{w}}\left(T_{\mathrm{w}}-T_{\mathrm{f}}\right) \Delta z,
$$

where $\rho_{\mathrm{w}}$ is the density of fresh water $\left(1000 \mathrm{~kg} \mathrm{~m}^{-3}\right), c_{\mathrm{w}}$ is the specific heat of water $\left(4185 \mathrm{~J} \mathrm{~kg}^{-1} \mathrm{~K}^{-1}\right),(\Delta z$ is the depth interval of the water layer, $T_{\mathrm{w}}$ is the average temperature of the water in the interval $\Delta z$ and $T_{\mathrm{f}}$ is the freezing temperature of the water. The salinity-determined freezing point of sea water is calculated by the Millero (1978) equation:

$$
\begin{aligned}
T_{\mathrm{f}}= & -0.0575 S+0.001710523 S^{3 / 2} \\
& -0.0002154996 S^{2}-0.00753 p,
\end{aligned}
$$

where $S$ is the salinity of the water in psu and $p$ is pressure in bars. In this particular case, where the pressure is negligible, the first term of this equation dominates the calculation.

The time series of the distribution of heat in the top $2 \mathrm{~m}$ of the water in the lead adjacent to the Seattle site is presented in Figure 3c. Summing over the $2 \mathrm{~m}$ depth to obtain the total heat content in this layer, we observed that there was a rapid increase in the heat content beginning around 4 July (Fig. 5). By 10 July the heat content had increased from $3.6 \mathrm{MJ} \mathrm{m}^{-2}$ to $7.1 \mathrm{MJ} \mathrm{m}^{-2}$. During this period the surface water layer had dramatically thickened, decreased in salinity and increased in temperature (Fig. 3a and b). From 10 July until 24 July the total heat content in the top $2 \mathrm{~m}$ layer fluctuated between 5.1 and $7.7 \mathrm{MJ} \mathrm{m}^{-2}$, but remained relatively high. The fluctuations in the heat content reflect the changes in the temperature of the water in the top of the leads (Fig. 3b and c). Between 24 and 28 July, there was a rapid decrease in the total heat content, coinciding with the increase in wind speed and floe speed (Fig. 1) and divergence of the ice floes around Ice Station SHEBA (Fig. 2). From 28 July through 9 August (when the 


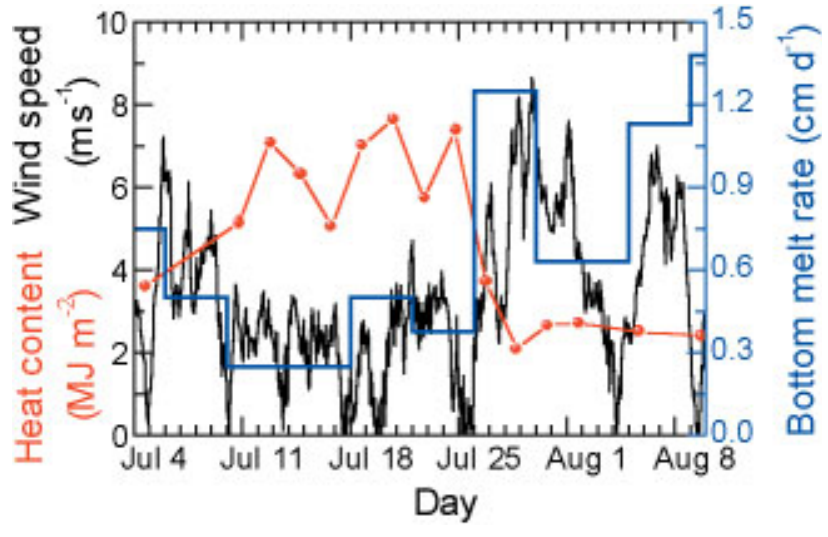

Fig. 5. Time series of wind speed, heat content in the top $2 \mathrm{~m}$ of the lead adjacent to Seattle and melt rate at the bottom of the undeformed multi-year ice at the Seattle site, 4 July-10August 1998.

lead measurements ended) the total heat content remained relatively constant at $2.6 \mathrm{MJ} \mathrm{m}^{-2}$.

Measurements from the mass-balance sites at the Seattle site (Perovich and Elder, 2001) indicate that the rapid decrease in the heat content coincided with an increase in the rate of melting at the bottom of the ice cover (Fig. 5). Between 4 and 26 July, the average bottom melt rate was about $0.4 \mathrm{~cm} \mathrm{~d}^{-1}$. Between 26 and 30 July, this rate increased to $>1.2 \mathrm{~cm} \mathrm{~d}^{-1}$, for a total loss of about $4.8 \mathrm{~cm}$. This result implies that the movement of the ice cover played an important role in determining the amount of heat exchanged between the ice and the surrounding and underlying water. Under quiescent conditions the heat stored in the warm fresh-water layer can only be delivered to the ice immediately adjacent to it. The increased movement of the ice within this layer increases the efficiency of heat transfer at the ice-ocean interface. This situation is analogous to an ice-water bath. Indeed, instructions for preparing an icewater bath always stress the importance of stirring the ice and water mixture to achieve a uniform temperature of $0^{\circ} \mathrm{C}$. This observation is also consistent with the findings of McPhee (1983, 1992), who demonstrated that the heat flux between the bottom of the ice and the ocean is a function not only of the temperature elevation of the water above freezing, but also of the stress at the interface and the effective drag on the underside of the ice. As ice velocity increases, there is a corresponding increase in the interfacial stress and effective drag, which act together to increase the heat flux at the ice-ocean interface.

\section{SUMMARY}

Combined measurements of ice mass balance, water temperature and salinity in the top of leads, and the distribution of open-water areas, indicate that, under summer conditions, ice dynamics continues to play an important role in the surface heat budget of the Arctic Ocean. This is because the movement of the ice cover can cause dramatic changes in the characteristics of the ice-ocean matrix that affect the energy budget. In the summer the ice pack becomes a complex, evolving mosaic of ice and open water and its movement is closely correlated with wind and water stresses. In contrast to winter conditions, there is little resistance to movement due to the interaction of individual pieces of ice. When winds are light, there is little change in the relative location of the ice floes, even though the region as a whole undergoes translation. Under these quiescent conditions, meltwater from the surface of the ice runs off into the adjacent leads. Because the fresh water is more buoyant than the underlying ocean water, the meltwater runoff forms a stable fresh-water lens on top of the leads. This relatively fresh layer is warmed by the absorption of solar energy, providing further stability. If these calm conditions persist, the warm fresh-water layer at the top of the open water increases in depth and can potentially extend laterally below the adjacent ice cover. When wind speed and corresponding ice-floe speed reach a threshold level, the warm fresh-water layer mixes with the underlying ocean. Heat stored in both the freshwater layer and the underlying ocean is then more effectively delivered to the sides and bottom of the ice cover, causing melting rates to increase.

In addition to increasing the efficiency of heat exchange within the atmosphere-ice--ocean system, the impact of higher wind stresses on the ice cover can lead to significant changes in the distribution of the ice and open water in a region. Open water has an albedo of about 0.06 (Pegau and Paulson, 1999). A melting sea-ice cover has an average albedo of $0.6-0.7$ (Perovich and others, in press a). Consequently, a significant change in the relative amounts of open water and a melting ice cover will result in a corresponding change in the areally averaged albedo (Perovich and others, in press b).

\section{AGKNOWLEDGEMENTS}

The authors appreciate the support of the U.S. National Science Foundation and the Office of Naval Research. They are particularly indebted to the crew of the Canadian Coast Guard ice-breaker Des Groseilliers and the logistics crew from the Applied Physics Laboratory, University of Washington, for their tremendous support during the SHEBA field program.

\section{REFERENGES}

Andreas, E. L., M.W. Miles, R. G. Barry and R. C. Schnell. 1990. LIDARderived particle concentrations in plumes from Arctic leads. Ann. Glaciol., 14, 9-12.

Badgley, F. J. 1966. Heat budget at the surface of the Arctic Ocean. In Fletcher, J. O., ed. Proceedings of Symposium on the Arctic Heat Budget and Atmospheric Circulation. Santa Monica, CA, Rand Corporation, 267-277. (Memorandum RM-5233-NSF.)

Coon, M. D., G.S. Knoke, D. C. Echert and R. S. Pritchard. 1998. The architecture of an anisotropic elastic-plastic sea ice mechanics constitutive law. 7. Geophys. Res., 103 (C10), 21,915-21,925.

Golovin, P. M., S.V. Kochetov and L. A. Timokhov. 1994. Details of thermohaline structure of summer Arctic ice glades. Oceanology, 33(6), 735-739.

Gow, A. J., D. A. Meese, D. K. Perovich and W. B. Tucker, III. 1990. The anatomy of a freezing lead. 7. Geophys. Res., 95 (C10), 18,221-18,232.

Maykut, G. A. 1978. Energy exchange over young sea ice in the central Arctic. 7. Geophys. Res., 83(C7), 3646-3658.

Maykut, G. A. 1982. Large-scale heat exchange and ice production in the central Arctic. 7. Geophys. Res., 87(C10), 7971-7984.

McPhee, M. G. 1980. An analysis of pack ice drift in summer. International Association of Hydrological Sciences Publication 124 (Symposium at Seattle 1977 - Sea Ice Processes and Models), 62-75.

McPhee, M. G. 1983. Turbulent heat and momentum transfer in the oceanic boundary layer under melting pack ice. f. Geophys. Res., 88(C5), 2827-2835.

McPhee, M. G. 1992. Turbulent heat flux in the upper ocean under sea ice. 7. Geophys. Res., 97 (C4), 5365-5379.

McPhee, M. G., G. A. Maykut and J. H. Morison. 1987. Dynamics and thermodynamics of the ice/upper ocean system in the marginal ice zone of the Greenland Sea. 7. Geophys. Res., 92(C7), 7017-7031.

Millero, F. J. 1978. Appendix 6. Freezing point of sea water. In Eighth report of 
the foint Panel on Oceanographic Tables and Standards. Paris, Unesco, 29-31. (Technical Papers in Marine Science 28.)

Morison, J. H., M. G. McPhee, T. B. Curtin and C. A. Paulson. 1992. The oceanography of winter leads. F. Geophys. Res., 97(C7), 11,199-11,218.

Nansen, F. 1902. The Norwegian North Polar Expedition 1893-1896: scientific results. Christiania, Jacob Dybwad.

Overland, J. E., S. L. McNutt, S. Salo, J. Groves and S. Li. 1998. Arctic sea ice as a granular plastic. F. Geophys. Res., 103 (C10), 21,845-21,867.

Pegau, W. S. and C. A. Paulson. 1999. The effects of clouds on the albedo of Arctic leads. [Abstract.] EOS, $\mathbf{8 0}(46)$, Fall Meeting Supplement, F221.

Perovich, D. K. and B. C. Elder. 2001. Temporal evolution of Arctic sea-ice temperature. Ann. Glaciol., 33 (see paper in this volume).

Perovich, D. K. and G. A. Maykut. 1990. Solar heating of a stratified ocean in the presence of a static ice cover. F. Geophys. Res., 95(C10), 18,233-18,245.

Perovich, D. K. and J. A. Richter-Menge. 2000. Ice growth in springtime leads. 7. Geophys. Res., 105(C3), 6541-6548.

Perovich, D. K. and 8 others. 1999a. SHEBA: snow and ice studies. Hanover, NH, U.S. Army Corps of Engineers. Cold Regions Research and Engineering Laboratory.

Perovich, D. K. and 22 others. 1999b. Year on ice gives climate insights. EOS, 80 (41), 481, 485-486.

Perovich, D. K., T. C. Grenfell and B. Light. In press a. The seasonal evolution of Arctic sea ice albedo. 7. Geophys. Res.

Perovich, D. K., W. B. Tucker, III and K. A. Ligett. In press b. Aerial obser- vations of the evolution of ice surface conditions during summer 7 Geophys. Res.

Pinto, J. O. and J. A. Curry. 1995. Atmospheric convective plumes emanating from leads. 2. Microphysical and radiative processes. 7. Geophys. Res., 100 (C3), 4633-4642.

Pinto, J. O., J. A. Curry and K. L. McInnes. 1995. Atmospheric convective plumes emanating from leads. 1. Thermodynamic structure. 7. Geophys. Res., $100(\mathrm{C} 3), 4621-4631$

Richter-Menge, J. A. and B. C. Elder. 1998. Characteristics of pack ice stress in the Alaskan Beaufort Sea. 7. Geophys. Res., 103(C10), 21,817-21,829.

Schnell, R. C. and 7 others. 1989. Lidar detection of leads in arctic sea ice. Nature, 339(6225), 530-532.

Smith, R. C. 1973. Optical properties of the Arctic upper water. Arctic, 26(4), 303-313.

Smith, S. D., R. D. Muench and C. H. Pease. 1990. Polynyas and leads: an overview of physical processes and environment. F. Geophys. Res., 95(C6), 9461-9479.

Steele, M., J. Zhang, D. Rothrock and H. Stern. 1997. The force balance of sea ice in a numerical model of the Arctic Ocean. 7. Geophys. Res., 102 (C9), 21,061-21,079.

Wettlaufer, J. S., M. G. Worster and H. E. Huppert. 2000. Solidification of leads: theory, experiment and field observations. 7. Geophys. Res., $105(\mathrm{Cl}), 1123-1134$ 